\title{
ENTRE O Político e o SAgRAdo: O HOMO SACER CONTEMPORÂNEO ${ }^{1}$
}

\author{
BETWEEN THE POLITICAL AND THE SACRED: THE CONTEMPORARY HOMO \\ SACER
}

\author{
GLAUCO BARSALINI $\left.{ }^{*}\right)$ \\ Ricardo Geraldo De CARvalho ${ }^{(* *)}$
}

\begin{abstract}
RESUMO
Este artigo tem como objetivo salientar o estado de exceção em caráter permanente, constituinte medular dos regimes democráticos na contemporaneidade, gerador da tensão entre $o$ ressentimento - fomentador do poder soberano - e a elaboração de uma nova ética, com novos princípios humanizadores. A materialização desta incongruência apresenta-se na figura do homo sacer - sujeito que pode ser radicalmente desprezado e, no limite, aniquilado, sem que tal ato seja passível de pena àqueles que a isso tenham dado causa - por ser paradoxal, na medida em que é excluído, lançado em uma zona indeterminada, tornando-se invisível para o biopoder. Em contrapartida, sua sobrevivência denuncia a presença do estado de exceção, aflorando a urgência da profanação dos mecanismos que foram sacralizados pela biopolítica. Entre o político e o sagrado depara-se com a politização da morte na medida em que a exceção, vivenciada nos campos de concentração e nos presídios, é transplantada para fora destas realidades. Esta flutuação da morte de zonas sombrias, para contextos teoricamente ordinários, propicia discrepâncias entre técnica e ética, medicina e direito, preservação da vida e dignidade humana. Defronta-se com questões de profundo teor bioético quando a vida nua é exposta em sua extrema vulnerabilidade.
\end{abstract}

PalaVras-Chave: Estado de Exceção. Homo sacer. Sacralização. Bioética. Vulnerabilidade.

\section{ABSTRACT}

This article aims to highlight the state of exception in a permanent, a fundamental element of democratic regimes in the contemporary world, which generates the tension between resentment - fomenting sovereign power - and the elaboration of a new ethics, with new humanizing principles. The materialization of this incongruity appears in the figure of the homo sacer - subject who can be radically despised and, at the limit, annihilated, without such an act being liable to punishment to those who have given it cause - for being paradoxical, inasmuch as is excluded, cast into an indeterminate zone, making it invisible to biopower. On the contrary, its survival denounces the presence of the state of exception, bringing out an urgency of the desecration of the mechanisms that have been sacralized by biopolitics. Between the political and the sacred one faces the politicization of death insofar as the

${ }^{1} \mathrm{O}$ presente artigo é fruto de debates realizados pelos autores em três fóruns de discussão: no FT Espaço Religioso: entre o público e o privado, do $29^{\circ}$. Congresso Internacional da SOTER - Tempos do Espírito: inspiração e discernimento, de 12 a 14 de julho de 2016; no IX Encontro Luso Brasileiro de Bioética e III Encontro Lusófono de Bioética, ocorrido na Universidade Católica Portuguesa - Porto - entre os dias 15 e 17 de setembro de 2016 (do qual participou exclusivamente o coautor Ricardo Geraldo de Carvalho); e no Grupo de Pesquisa Ética, Política e Religião: questões de fundamentação, vinculado ao Programa de PósGraduação Stricto Sensu de Ciências da Religião da Pontifícia Universidade Católica de Campinas. Fragmentos das comunicações apresentadas no Congresso e no Encontro compõem este texto, aos quais se somaram e articularam novas reflexões, elaboradas justamente das discussões realizadas ao longo de 2016 sobre a temática.

(*)Professor Pesquisador do Mestrado em Ciências da Religião e da Faculdade de Ciências Sociais da Pontifícia Universidade Católica de Campinas. E-mail: glaucobarsalini@gmail.com.

(**)Mestrando; Filiação Institucional: Pontifícia Universidade Católica de Campinas; Instituição financiadora da pesquisa: CAPES e PUC-Campinas. E-mail: rg77carvalho@gmail.com 
exception experienced in concentration camps and prisons is transplanted out of these realities. This fluctuation of the death from dark areas to theoretically ordinary contexts, provides discrepancies between technique and ethics, medicine and law, preservation of life and human dignity. It is confronted with questions of deep bioethical content when naked life is exposed in its extreme vulnerability.

KEYWORDS: State of Exception. Homo Sacer. Sacralization. Bioethics. Vulnerability.

\section{INTRODUÇÃO}

A sistemática perseguição às etnias minoritárias tem transformado, nos séculos XX e XXI, muitas pessoas em apátridas e em refugiados ${ }^{2}$, e o campo, tanto no passado quanto no presente, é o espaço que confere materialidade a esse processo de exclusão.

Os campos de concentração nazifascistas constituíram-se como a experiência mais radical que o ocidente moderno poderia presenciar de incontroversa e deliberada violação da vida humana3, espaços em que pessoas foram convertidas em cobaias humanas, transformadas em fantasmas vivos, lançadas num limiar ético absolutamente inaudito, revelador de uma espécie de falência ética das sociedades contemporâneas.

Os campos de refugiados atuais, por sua vez, compõem-se como habitat, temporário ou permanente, do "rejeito" humano, das massas de populações que se vêem obrigadas a fugir de seus países por terem perdido - ou por estarem na iminência de perder - tudo o que possuíam ou que possuem: seus lares, parentes, amigos, meios de sustento. Nos últimos anos, centenas de milhares de pessoas têm sido forçadas a abandonar seus países de origem, seja por cataclismos naturais - Indonésia e Haiti -, seja por guerras civis - Congo, Nigéria, Líbia, Iêmen, Egito, Bósnia-Herzegovina, Ucrânia, Síria. Tanto quanto bens materiais e entes queridos, essas pessoas perdem, também, sua identidade de nacionais tornando-se, no mais das vezes, apátridas, sujeitos destituídos de quaisquer direitos de cidadania, a quem resta apenas, quando muito, a expectativa de acesso aos direitos humanos.

\footnotetext{
2 Luís Renato Vedovato (2013) promove importante discussão acerca da situação dos apátridas e refugiados no mundo contemporâneo. Inventaria a problemática no contexto internacional e defende o direito do ingresso mediante o controle internacional da decisão dos Estados-Nação. Em oposição ao atual império da exclusão das minorias e amparado na "teoria das escolhas trágicas", de G. Calabresi e P. Bobbit, Vedovato advoga que os impactos da crise que o mundo enfrenta na atualidade "demonstram a necessidade de responsabilização, em termos globais, e a afirmação mais vigorosa da responsabilidade dos Estados no tocante ao respeito, à proteção e à satisfação dos direitos sociais, que não encontram, juridicamente, barreiras nas fronteiras políticas nacionais.” (VEDOVATO, 2013, p. 57).

3 No oriente, os gulags soviéticos (os "moedores de carne") materializaram o confinamento de milhares de pessoas perseguidas pelos regimes, as quais eram submetidas às mais terríveis práticas de opressão: interrogatórios, torturas, trabalhos forçados e morte prematura (vide OLIVEIRA, 2005). Não ficaram atrás dos gulags os laogai chineses que, encobertos pelo discurso revolucionário da "reeducação" foram espaços para o exercício de desmesurada opressão do regime a uma enormidade de seres humanos (vide WILLIAMS e WU, 2004).
} 
No passado, como no presente, defrontamo-nos com a instalação incômoda e inescapável, do estado de exceção. Cristalizada no campo, a exceção se torna, desde os regimes totalitários do século XX até a atualidade, a regra, desafiando as democracias contemporâneas que se negam ou, no melhor dos cenários, titubeiam, reiteradamente, em acolher tais refugiados. Os totalitarismos do passado, assim como as ditaduras do presente, enlaçados entre si num jogo originalmente violento e repetidamente beligerante de relações políticas, econômicas, culturais e religiosas com as democracias, têm produzido, sistematicamente, homo sacer, vidas nuas, sujeitos que podem ser radicalmente desprezados e, no limite, aniquilados, sem que tal ato seja passível de pena àqueles que a isso tenham dado causa. Passado e presente despejam sobre a mesa tudo aquilo que talvez a civilização hodierna mais tenha dificuldade de encarar: o enredamento entre a memória, o testemunho e o ressentimento.

Este artigo reflete sobre o conceito de homo sacer desenvolvido por Giorgio Agamben. Produto da violência mítica ${ }^{4}$ sobre a qual se erguem os Estados Moderno e Contemporâneo, fruto da mais radical secularização do mundo5, resultado do ressentimento nutrido pelas nações, o homo sacer é aquele que não pode testemunhar e, bem por isso, paradoxalmente, é o elemento chave de certa memória, a de que não podemos nos esquecer, para que não incorramos no risco de repetir os erros do passado.

É a respeito dessas questões que trataremos logo a seguir.

\section{MEMÓRIA TESTEMUNHO E RESSENTIMENTO}

Ao interpretar o pensamento de Giorgio Agamben no que concerne ao messianismo e à política, o filósofo brasileiro Oswaldo Giacoia Junior constata que $\mathrm{o}$ pensador italiano reflete a proposta nietzschiana de assumir integralmente o passado, vencendo, com esta atitude, o espírito da vingança: nesta era, em que a exceção tornou-se a regra, refuta-se a ética de Nietzsche, na qual o ser humano é a contradição, tomando a forma de promessa, em que a contradição ontológica do ser humano é aquela que se coloca no espaço entre o

\footnotetext{
4 Em “Crítica da Violência - Crítica do Poder" Walter Benjamin (1986) identifica o poder soberano (schaltende Gewalt) como o poder mítico, aquele que institui o direito (waltende Gewalt). Para ele, ambos, diferentemente do poder divino, são violentos. Agambem fundamenta-se no conceito de violência concebido por Benjamin para compreender o bando soberano, raiz do homo sacer.

5 Para Nietzsche (2001), a sacralização do profano promovida na modernidade criou uma sociedade radicalmente descrente do transcendente. Em nossa sociedade, tudo é imanente e não há qualquer espaço para a transcendência mesmo que na imanência. Agamben inverte a sentença e propõe como saída para essa realidade, o contrário da sacralização do profano, a saber, a profanação do sagrado.
} 
esquecimento e a promessa. Refuta-se, pois, a incondicional aceitação própria do amor fati pelo indivíduo, a aceitação integral da vida, com suas circunstâncias inerentes ao ser humano, mesmo em seus aspectos mais cruéis e dolorosos. Reitera-se deliberadamente o "ressentimento, como um resto que permanece entre o não assimilável - cuja repetição não pode ser querida - e o imperdoável, que não pode ser aceito nem esquecido, mas que, no entanto, nem por isso não deixa de se repetir" (GIACOIA JUNIOR, 2015, p. 8).

A atualidade de Nietzsche não pode passar despercebida. A força do esquecimento entre os seres humanos é extraordinariamente poderosa, pois, diferentemente dos outros animais, os homens são capazes de prometer. $\mathrm{O}$ paradoxo criado no interior da natureza fomenta a antinatureza. Assim, o ser humano coloca em suspensão a força de seu esquecimento para que possa prometer e, por conseguinte, fazer cultura. Na relação do ser humano com o tempo, sem o esquecimento não existirá o presente. Logo, o presente é a dimensão nuclear do tempo e, nessa perspectiva, somente o ente que pode ser sujeito da ação é capaz de prometer, mantendo hodierno aquilo que não se encontra mais na dimensão do presente, mas é nutrido na memória. Prometer significa, portanto, responder, no futuro, a um empenho que se fez no passado e que, em função da memória, se mantém no presente. Em tal empenho estão contidos o direito, o ser humano e o tempo.

Nietzsche desvenda a relação dialética existente entre a memória e o esquecimento - o que equivale à ressignificação das experiências vividas -, a qual preserva os acontecimentos no presente. O presente é possível por causa do esquecimento; todavia, não se preserva no presente sem que se tenha a memória. Pode-se compreender estes acontecimentos como resiliência, ou seja, a capacidade que temos para lidar com os problemas, por mais graves que possam ser, superando-os ou simplesmente resistindo a eles sem sucumbir à situações dolorosas e desafiantes que tentam, ao extremo, nossa capacidade de suportar pressões e sofrimentos (PEREIRA, 2015)

A promessa é o solo originário da fórmula causal na mente humana, na medida em que o devir humano fixa de alguma maneira o animal não fixado e estabiliza de algum modo o animal não estabilizado. Ela deságua no campo antropológico quando a estabilização se dá na dialética entre memória e esquecimento, fomentando a incondicional aceitação do amor fati pelo indivíduo, a aceitação integral da vida. Aqui, o homem assume tudo o que constitui a vida, até mesmo a maior das crueldades e das dores que a ela se imponham. Nietzsche habilmente explicita o espírito livre ao afirmar: 
Sempre que alguém fala sem amargura do homem, como de um ventre que tem duas classes de necessidades e de uma cabeça que tem uma; sempre que alguém não busque e não queira ver outra coisa que a fome, o instinto sexual e a vaidade, como se estas fossem as tendências essenciais e únicas no fundo das ações humanas; em suma, sempre que alguém fala mal dos homens e não com malícia, o que ama o conhecimento deve escutar com atenção e diligência, deve ter o ouvido alerta, onde se fala sem despeito. Já que o homem despeitado e que sempre lacera a si mesmo com os próprios dentes (ou em seu lugar o mundo, Deus ou a sociedade) poderá talvez, falando segundo o critério da moral, estar à maior altura que o sátiro risonho e autossatisfeito, mas em todos os outros sentidos se nos apresenta como o caso mais comum, mas indiferente e menos instrutivo. Ninguém mente tanto quanto o despeitado (NIETZSCHE, 2014, p. 39).

A ética nietzscheniana opõe-se à supressão das diferenças, à padronização de valores que, sob o pretexto de universalidade, encobrem, de fato, a imposição autoritária de interesses particulares; por isso, ela é também opositora da igualdade entendida como uniformidade. Nietzsche denuncia a transformação de pessoas em peças anônimas do biopoder e a manipulação de corações e mentes pelos grandes dispositivos formadores de opinião (GIACOIA JUNIOR, 2000). Parece não ter surgido, ainda, esse novo homem, dotado de uma ética que o constitua como o para além do homem, em superação ao modelo moderno (e contemporâneo) do homem doente. Com a famosa frase "Deus está morto", inscrita no aforismo 125 de A Gaia Ciência, Nietzsche coloca às claras o definitivo ingresso da humanidade na esfera da razão esclarecida. A absoluta emancipação da razão promovida pelo advento da modernidade - em substituição à metafísica tradicional e ao conjunto de valores próprios a ela conduzirá, inevitavelmente, à sacralização do profano e ao aparecimento do fundamentalismo hedonista da sociedade de consumo, sintoma inequívoco do niilismo ${ }^{6}$. A leitura de Nietzsche conduz à compreensão de que na cotidianidade o ethos é assassinado por regimes de estado que validam atrocidades diametralmente contraditórias aos princípios da bioética e, por conseguinte, da vida. E aqui se situa a descoberta de Giorgio Agamben. O estado de exceção de caráter permanente que constitui o cerne das democracias contemporâneas estabelece uma importante tensão entre o ressentimento, amigo íntimo do poder soberano que dá origem a tal estado, e a possibilidade de formulação de uma nova ética, de novos princípios orientadores para a humanidade. E o núcleo dessa tensão é justamente o homo sacer porque, se por um lado ele é objeto do expurgo, por outro, sua sobrevivência denuncia a presença do estado de exceção e do ressentimento, que nutre e que ao mesmo tempo é nutrido, pelo poder soberano hodierno, chamando atenção para a urgência da necessidade de

${ }^{6}$ Veja-se Oswaldo Giacoia Junior no Youtube: Nietzsche - A Morte de Deus, 2017. 
dissolução dos pilares da sacralização do mundo. O homo sacer encerra, no seu próprio corpo, a totalidade do cosmos do bando soberano, todo o universo de tensões que habitam a política e a economia contemporânea. Cada ferida que se abre na carne da vida nua expressa as marcas indeléveis do poder implacável da política e da economia atuais, hábeis no incansável e inesgotável exercício da biopolítica para a efetivação do biopoder. É sobre o que discorreremos na sequência.

\section{COISIFICAÇÃO DA VIDA: O PODER E A POLÍTICA DA DESUMANIZAÇÃO}

O "eclipse do valor da vida" é constatado em fatos e em situações de grande alcance e profundidade. A vida humana é desvalorizada e atacada desde sua fase inicial até seu momento final, persistindo ameaças que ferem a dignidade da pessoa, gerando o sofrimento e a coisificação dos indivíduos (VIDAL, 1997, p. 11-12). Giorgio Agamben (2012) demonstra o processo de transferência do sagrado que ocorre na passagem entre o mundo teocrático e o secularizado. A secularização não superou, de acordo com o filósofo, a sacralização das relações políticas, econômicas, sociais e religiosas, proibindo os indivíduos de efetivamente acessarem a res publica, sua mais importante promessa. Tal como o Estado teocrático cuidava de glorificar o Reino de Deus, o Estado secularizado glorifica o poder soberano utilizando-se, para tanto, do ritual, assim como fazia aquele que o precedeu. No mundo secularizado, o poder soberano se ergue sobre a necessária exclusão de seres humanos, criando uma zona cinzenta, intermediária, para onde são lançados os indivíduos excluídos, suscetíveis a todo tipo de infortúnio. Aqui, os princípios éticos tornam-se efêmeros, projetando uma sombra sinistra sobre as práticas correntes nas condutas relacionais entre as pessoas, criando mecanismos que corrompem as decisões que refletem no espaço público, estigmatizando profundamente os indivíduos em sua dignidade, alteridade e autonomia e, enfim, despojando tais sujeitos até mesmo dos recursos necessários para resguardar a inviolabilidade da vida. Se atitudes que desumanizam não foram questionadas numa perspectiva ética de modo a afetar os indivíduos que orquestraram a mais profunda exclusão humana no interior dos governos totalitários, cabe perguntar: como é possível que também as democracias produzam a desumanização?

O debate bioético que ora se apresenta demanda algumas considerações acerca da construção histórica e social da biopolítica e do biopoder. O conceito de vida nua trazido por Agamben tem paralelo com a microfísica do poder de Michel Foucault. Em aula proferida a 17 de março de 1976, o pensador francês 
(FOUCAULT, 2005, p. 288-289) estabelece distinção entre o direito do soberano e o direito político do século XIX: enquanto o do primeiro era o de "fazer morrer ou de deixar viver", o do segundo passa a ser o de "fazer viver e de deixar morrer". Ele demonstra a radical mudança por que passou o Estado, desde os tempos do gládio à constituição de um direito de natureza nos séculos XVII e XVIII, e de um novo modelo de Estado, nos séculos seguintes. A soberania feudal deu lugar à disciplina, estabelecendo-se, entre os séculos XVIII e XIX, as sociedades disciplinares: classificatórias, normalizadoras, vigilantes e punitivas, promotoras de uma "pressão punitiva ao mesmo tempo minúscula e contínua", classificações, vigilância e punições estas, dirigidas ao corpo humano. Na segunda metade do século XVIII, surgiu, entretanto, "uma outra tecnologia de poder [...] que não exclui a técnica disciplinar, mas que a embute, que a integra, que a modifica parcialmente e que, sobretudo, vai utilizá-la implantando-se de certo modo nela”. Essa nova tecnologia de poder não tem mais como foco o corpo humano individual, mas sim a espécie humana; nesse sentido, ela não individualiza como fazia a anterior, mas ela se dirige "a uma massa global, afetada por processos de conjunto que são próprios da vida, que são processos como o nascimento, a morte, a produção, a doença, etc.”. Tratase, tal tecnologia, que se fixa então no final do século XVIII, daquilo de Foucault denomina "biopolítica da espécie humana". Se se assistiu ao surgimento das "ciências do indivíduo" nos séculos XVII e XVIII, em que "o corpo foi 'subjetivado' [...] foi psicologizado [...] foi normalizado", vê-se, no final do XVIII, o nascimento da "biopolítica da espécie humana". Segundo o filósofo, nesse momento é que se cria um racismo de Estado, aquilo que o leva a escolher que seres humanos "devem viver" e que seres humanos "podem morrer". "Fazer morrer ou deixar viver" remete ao exercício do poder do soberano, que escolhia contra quem guerreava ou não guerreava, que novo solo ocupava, quais de seus inimigos deveriam ser massacrados, quais deles deveriam ser escravizados, e quais deveriam viver em condições parecidas com a de homens livres. O limite entre a vida e a morte estava dado pela escolha pessoal do soberano, pelo direito do soberano, aquele que detinha maior força e que por isso se impunha. $\mathrm{O}$ príncipe escolhia, então, pela vida ou pela morte, fazia morrer ou simplesmente deixava viver. Por outro lado, "fazer viver e de deixar morrer" significa também escolher que populações (e não mais exclusivamente corpos individuais) devem viver e que populações podem morrer, mas não exatamente quem deve morrer. Está-se aqui em um universo jurídico muito diferente daquele em que quem comandava era o soberano, pois está-se diante de um Estado biopolítico, motivo 
pelo qual o seu direito formula-se como técnica, ciência. A garantia da vida ou o abandono à morte se dão, portanto, a partir de um direito biopolítico. A vida sendo garantida pela regra, e a morte sendo permitida pela exceção, exceção esta que, como demonstra Giorgio Agamben (2002; 2005; 2008), tem sua abertura na própria regra e que, contemporaneamente, terá como síntese uma nova sentença: "já não fazer morrer, nem fazer viver, mas fazer sobreviver" (AGAMBEN, 2008, p. 155). O Estado moderno é o "Estado tecnológico", ou então um "Estado técnico", cuja existência está intimamente ligada à emergência e permanência do biopoder, o poder que controla os corpos e a própria vida: é o Estado racista, o Estado contemporâneo.

O nacional-socialismo alemão impôs a mais radical politização da morte. No processo de Nuremberg, os experimentos conduzidos pelos médicos e pesquisadores alemães sobre as cobaias humanas (Versuchepersonen - VP) nos campos de concentração foram universalmente considerados como um dos capítulos mais infames na história do nazismo. Desgraçadamente, situações desumanizadoras foram reproduzidas em contextos teoricamente regidos pela democracia. Experimentos com detentos e condenados à morte haviam sido conduzidos muitas vezes e em larga escala no século XX, fundamentalmente nos Estados Unidos, país que disponibilizou o maior número de juízes para o tribunal de Nuremberg (AGAMBEN, 2002). Neste ínterim, desvela-se um espaço que coisifica a pessoa ao emergirem questões de profundo teor bioético, as quais trazem à reflexão as oscilações entre decisão médica e decisão legal. A morte dos pacientes torna-se, deste modo, um fenômeno produzido pela mais radical influência da técnica médica, sendo plausível atestar que os corpos de pessoas mantidas em coma induzido na realidade entraram em uma zona de indeterminação, onde as palavras vida e morte haviam perdido seu significado, assemelhando-se ao espaço de exceção, habitado pela vida nua. Assim, as pessoas em situação de extrema vulnerabilidade, pacientes em fase terminal, foram sistematicamente lançadas à condição de homo sacer. Assujeitados, os internos foram despojados de todo estatuto político e reduzidos à vida nua no espaço da absoluta impossibilidade de decidir entre fato e direito, entre norma e aplicação, entre exceção e regra; foram submetidos a situações de extremo horror que incidiram constantemente na sua vida (ou sobrevida). Submergidos pelo biopoder, tornaram-se homo sacer. Na década de 1930, no Alabama (EUA), quatrocentos negros sifilíticos foram deixados sem tratamento a fim de que se pesquisasse a história natural da doença, caso que veio a público apenas em 1972. Muitos são os fatos: lembre-se, também, do caso Karen Ann Quinlan (1954-1985). A jovem entrou em estado vegetativo depois de um acidente 
rodoviário, e foi internada no Hospital St. Clair de New Jersey. Após o pedido do tribunal, uma comissão julgou, com parecer favorável, a retirada dos aparelhos que a mantinham viva, depois de nove anos em estado vegetativo (BENTO, 2008).

Ao encontro de Foucault, Agamben reflete sobre a determinação científica da vida, demonstrando que em certo momento da história humana a biologia passou a ditar a condição de morte, ao estabelecer definições sobre os limites entre a morte e a vida. Lembra-se dos estudos de P. Mollaret e M. Goulon publicados em 1959, em que se apontava a existência de um novo tipo de coma, o coma dépassé - "no qual à abolição total das funções da vida de relação corresponde uma abolição igualmente total das funções da vida vegetativa" (MOLLARET e GOULON apud AGAMBEN, 2002, p. 167). Tal constatação colocava em cheque a "verdade" até então definitiva sobre o limite entre a vida e a morte: a determinação da absoluta morte cerebral. Reacende-se, aí, o debate sobre a eutanásia, questão controversa, discussão infinda, debate que, no mundo contemporâneo, não encontra meios de se esquivar da ideia de "vida digna de ser vivida" ou, de seu revés, de "vida sem valor": sem valor biológico (a não ser como fonte de estudo da ciência médica), sem valor econômico e, por constituir-se como aquilo que permite a sua aniquilação, sem valor jurídico. $\mathrm{O}$ VP (Versuchepersonen) torna-se, aqui, o exemplo mais atual da vulnerabilidade humana daquele que está no limiar entre a vida e a morte, entregue à decisão da ciência:

A única resposta possível é a de que tenha sido decisiva, em ambos os casos, a particular condição das VP (condenados à morte ou detentos em um campo, o ingresso no qual significava a definitiva exclusão da comunidade política). Justamente porque privados de quase todos os direitos e expectativas que costumamos atribuir à existência humana e, todavia, biologicamente ainda vivos, eles vinham a situar-se em uma zona-limite entre a vida e a morte, entre o interno e o externo, na qual não eram mais que vida nua. Condenados à morte e habitantes do campo são, portanto, de algum modo inconscientemente assemelhados a homines sacri, a uma vida que pode ser morta sem que se cometa homicídio. $\mathrm{O}$ intervalo entre a condenação à morte e a execução, assim como o recinto dos lages, delimita um limiar extratemporal e extraterritorial, no qual o corpo humano é desligado de seu estatuto político normal e, em estado de exceção, é abandonado às mais extremas peripécias, onde o experimento, como um rito de expiação, pode restituí-lo à vida (graça ou indulto da pena são, é bom recordar, manifestações do poder soberano de vida e de morte) ou entregá-lo definitivamente à morte à qual já pertence. $O$ que aqui nos interessa especialmente, porém, é que, no horizonte biopolítico que caracteriza a modernidade, o médico e o cientista movem-se naquela terra de ninguém onde, outrora, somente o soberano podia penetrar (AGAMBEN, 2002, p. 166). 
Neste ínterim depara-se com a politização da morte na medida em que a exceção, vivenciada nos campos de concentração e nos presídios, é transplantada para fora destas realidades. Essa flutuação da morte de zonas sombrias, para contextos teoricamente ordinários, propicia discrepâncias entre técnica e ética, medicina e direito, preservação da vida e dignidade humana. Está-se frente a frente com questões de profundo teor bioético, as quais trazem à baila as oscilações entre decisão médica e decisão legal. A morte dos pacientes torna-se, deste modo, um epifenômeno da técnica adotada pelo médico, sendo plausível atestar que os corpos de pessoas mantidas em coma induzido, na realidade entraram em uma zona de indeterminação, onde as palavras "vida" e "morte" haviam perdido seu significado, assemelhando-se ao espaço de exceção, habitado pela vida nua. Assim, as pessoas em situação de extrema vulnerabilidade, pacientes em fase terminal, podem ser lançadas à condição de homo sacer.

Nesse contexto, ganha real importância a reflexão acerca da constatação de que entre os partidários mais inflamados da biopolítica moderna encontram-se pessoas que invocam a intervenção do Estado para decidir a respeito da finitude dos indivíduos mais fragilizados - que sobrevivem de forma artificial, sendo mantidas por meio de aparelhos e medicamentos, as funções básicas do corpo. $\mathrm{Na}$ atual politização da vida nua, que sinaliza que a biopolítica ultrapassou um novo umbral, as democracias modernas ostentam publicamente posturas que os nazistas receavam declarar (AGAMBEN, 2002, p. 170-172).

\section{O CAMPO NO PASSADO, O CAMPO NA ATUALIDADE}

Brutalmente, o nazismo definia as "vidas dignas" e as "vidas indignas" de serem vividas. Doentes, negros, judeus e homossexuais constituíam conjuntos de "vidas indignas" de serem vividas, a partir de certa defesa juridicamente articulada da eutanásia, que livra tal ação de qualquer tipificação de crime. E para onde vão aqueles cuja vida é “indigna de ser vivida"? Justamente para o campo, segundo Agamben, "o local onde se realizou a mais absoluta conditio inhumana que se tenha dado sobre a terra" (AGAMBEN, 2002, p. 175), em outras palavras, local da "vida exposta", da vida nua, do homo sacer, do homem que pode ser morto, mas não sacrificado, daquele que "pode morrer" e não daquele que "deve viver". Os que iam para os campos de concentração não necessariamente seriam mortos, mas estavam radicalmente suscetíveis à morte, e no mais das vezes acabavam mesmo sendo mortos. Mas o que é o campo? 
O campo é o espaço que se abre quando o estado de exceção começa a tornar-se regra. Nele, o estado de exceção, que era essencialmente uma suspensão temporal do ordenamento com base numa situação factícia de perigo, ora adquire uma disposição espacial permanente que, como tal, permanece, porém, estavelmente fora do ordenamento normal. (AGAMBEN, 2002, p. 175, 176, grifo nosso).

E o que teria criado as condições para a instalação e a permanência do campo? O estado de exceção, a saber:

O estado de exceção é o dispositivo que deve, em última instância, articular e manter juntos os dois aspectos da máquina jurídico-política, instituindo um limiar de indecidibilidade entre anomia e nomos, entre vida e direito, entre auctoritas e potestas. Ele se baseia na ficção essencial pela qual a anomia - sob a forma de auctoritas, da lei viva ou da força de lei - ainda está em relação com a ordem jurídica e o poder de suspender a norma está em contato direto com a vida. Enquanto os dois elementos permanecem ligados, mas conceitualmente, temporalmente e subjetivamente distintos - como na Roma republicana, na contraposição entre Senado e povo, ou na Europa medieval, na contraposição entre poder espiritual e poder temporal -, sua dialética - embora fundada sobre uma ficção - pode, entretanto, funcionar de algum modo. Mas, quando tendem a coincidir numa só pessoa, quando o estado de exceção em que eles se ligam e se indeterminam torna-se a regra, então o sistema jurídico-político transforma-se em uma máquina letal. (AGAMBEN, 2005 p. 130, 131).

Ora, é o que acontece no caso Alemão, em que Hitler torna-se o Führer e, então coincidem em uma só pessoa a auctoritas e a potestas. A força de teì7, mais do que substituir a lei ou sobre ela impor-se, passa a confundir-se com a própria lei, na medida em que o poder de suspendê-la incide como um bisturi sobre a vida, abrindo-lhe uma enorme chaga, revelando-lhe a própria nudez, tornando-a vida nua. O que sobreveio à $2^{a}$ Guerra Mundial já se conhece: uma "guerra fria" sucedida por um "neoimperialismo" intitulado globalização, em que o medo tomou conta de toda a geopolítica, a justificativa para a marcha armamentista de dois grandes blocos mundiais dos anos 40 aos 80 e, após a era Gorbachev, a justificativa para a manutenção e ampliação, pelo mundo, da "liberdade vigiada", ou da "doutrina da democracia norte-americana" que, atualmente, parece fazer renascer o conflito bipolar de dimensões planetárias, elegendo-se, novamente, como palco de disputas, o oriente médio, agora, destacadamente, a Síria.

A decorrência da política da expropriação calçada na ideologia do medo tem permitido o estabelecimento de uma divisória eugênica entre os que "devem

\footnotetext{
7 A força de tei é a antítese da própria lei. Corresponde, nas palavras de Agamben (2005), a uma "força, um elemento místico" liberados pela suspensão da lei formal, razão pela qual se marca o termo lei com um risco, a fim de que se destaque que lei e força de tei não são correspondentes entre si.
} 
viver" e os que "podem morrer", produzindo inúmeros campos esparramados pelo mundo. Seja na Bósnia ou na Croácia, seja na Palestina ou em Ruanda, seja no Haiti ou em qualquer outro lugar do mundo, em países considerados emergentes, mas que socialmente apresentam condições de profundas desigualdades e, até, em países da Europa, ou da América do Norte, os campos estão cada vez mais presentes. É neles que se encontram os refugiados, os miseráveis, os "sem nada", aqueles que, tal como os que vivem uma vida vegetativa, "vivem indignamente", são a expressão concreta do império do permanente estado de exceção. Pois a existência da soberania implica necessariamente na existência do bando, do homo sacer, cujo espaço de sobrevivência e de morte é o campo. Pois não há soberania sem miséria humana; tal como não haveria poder de matar sem a existência do ser humano aniquilável; e não há biopoder sem a existência das populações que "podem morrer”, assim como não há biopoder sem a existência das populações que "devem viver". Desta feita, o que seriam os direitos humanos? Se, por um lado, refletem o avanço jurídico de lutas sociais do passado, por outro, por mais chocante que possa ser, conformam um aparato jurídico elaborado para sustentar o poder soberano, já que a manutenção desse poder implica na necessária manutenção da sobrevida do homo sacer.

Constituindo-se como regra e como exceção, o direito contemporâneo abrese para um soberano que se apresenta como uma máquina de poder assentada sobre a técnica (que dita as regras da vida e da morte), cujo discurso e cuja ação realizam um movimento pendular entre a biopolítica e a tanatopolítica, tendo, nos direitos humanos, o sustentáculo jurídico para a permanência do homo sacer e de seu espaço de sobrevivência e de morte: o campo, leia-se as favelas, os bairros pobres, os campos de refugiados, as prisões, os manicômios, as instituições para onde vão as crianças que delinquiram e, hoje, cada vez mais, a própria rua (espaço outrora público por excelência); espaços que o Estado resiste em ocupar, a não ser pela via da exceção: quando o soberano decide exercer a sua violência.

$\mathrm{Na}$ associação que faz do refugiado contemporâneo ao homo sacer, Agamben (2004; 2015) remete a Hanna Arendt. No capítulo intitulado "O declínio do Estado-Nação e o fim dos direitos do homem”, de Origens do Totalitarismo, a filósofa relata o processo dos deslocamentos de grupos étnicos e políticos minoritários pelos Estados hegemônicos europeus no entre guerras, os quais se utilizavam de instrumentos legais para desnacionalizar aqueles que a tais 
grupos pertenciam ${ }^{8}$. O enganoso caminho dos Tratados das Minorias, estabelecidos ao nível internacional com o intuito de disciplinar o convívio entre povos mais compactos e diversos entre si, aglutinando-os sob a égide de pequenos Estados, foi sucedido pelo aparecimento de povos sem Estado que simplesmente não tinham para onde ir. O ponto final de sua rota não demoraria a ser criado: o campo de concentração. Arendt escreve:

Mas, ao mesmo tempo, devemos lembrar que mal restava um país no continente europeu que não houvesse aprovado, entre as duas guerras, alguma legislação formulada de modo a permitir a rejeição do elevado número de seus habitantes a qualquer momento oportuno, mesmo que este direito não chegasse a ser usado.

Nenhum paradoxo da política contemporânea é tão dolorosamente irônico como a discrepância entre os esforços de idealistas bem-intencionados, que persistiam teimosamente em considerar "inalienáveis" os direitos desfrutados pelos cidadãos dos países civilizados, e a situação de seres humanos sem direito algum. Essa situação deteriorou-se, até que o campo de internamento - que, antes da Segunda Guerra Mundial, era exceção e não regra para os grupos apátridas - tornou-se uma solução de rotina para o problema domiciliar dos "deslocados de guerra" (ARENDT, 2006, p. 312).

À perda de seus lares somava-se a perda de direitos junto ao Estado, de proteção dos governos. Os refugiados que os sistemas totalitários do século XX criaram eram empurrados a essa condição por critérios de seletividade pautados no racismo (caso da Alemanha), na luta de classes (caso soviético) ou como resultado do conflito entre Estados. A maior angústia dos refugiados não residia na opressão, mas, muito pior, se a perda da condição que possibilitasse o seu reconhecimento enquanto cidadão já era inatingível, a ausência até mesmo da opressão revelava que eles já não tinham mais qualquer importância: o refugiado não gozava sequer da condição de ser oprimido. Passava, com isso, a um lugar de radical negação, tornava-se aquele em relação a quem ninguém mais se importava. Cometer o crime seria, para ele, um alento, pois, nesse caso, ganharia status de réu a quem se atribuem direitos. Do contrário, não teria qualquer status, pois o apátrida é exatamente o destituído de direitos.

O que mais choca é que a criação desse "sujeito de não direitos" se deu justamente na era em que a civilização moderna chegou ao seu ápice. Arendt escreverá:

O problema não é que essa calamidade tenha surgido não de alguma falta de civilização, atraso ou simples tirania, mas sim que ela não pudesse ser reparada,

\footnotetext{
${ }^{8}$ Exemplos disso foi o cancelamento em massa das naturalizações pela Alemanha, em 1933, que alcançou todos os judeus então naturalizados, transformando-os em apátridas; a formulação de leis na Bélgica, que permitiam a desnaturalização de pessoas por mero decreto; a desnaturalização de quarenta e cinco mil refugiados armênios pela Grécia, entre 1928 e 1936. (ARENDT, 2006, p. 310).
} 
porque já não há qualquer "incivilizado" na terra, pois, queiramos ou não, já começamos realmente a viver num Mundo Único. Só com uma humanidade completamente organizada, a perda do lar e da condição política de um homem pode equivaler à sua expulsão da humanidade. (ARENDT, 2006, p. 330).

A perda completa de direitos é, portanto, produto da civilização do século XX e, conforme Giorgio Agamben, também, das democracias atuais, que naturalizam a exceção, tornando-a regra. O ser humano destituído de qualquer significado, radicalmente individualizado e singularizado, conforme adjetiva Arendt (2006), não é agasalhado, definitivamente, por nenhum poder ou direito (nem mesmo pelos direitos humanos 9 ).

Agamben atualiza o debate reconhecendo no refugiado contemporâneo a figura daquele que está destituído de direitos, a inspirar a máxima arendtiana de que o problema central do século XX - e porque não dizer do século XXI - é o "direito a ter direitos". O pensador anotará:

Se os refugiados (cujo número nunca parou de crescer no nosso século [século $\mathrm{XX}$, até incluir hoje uma porção não desprezível da humanidade) representam, no ordenamento do Estado-nação moderno, um elemento tão inquietante, é antes de tudo porque, rompendo a continuidade entre homem e cidadão, entre nascimento e nacionalidade, eles põem em crise a ficção originária da soberania moderna. Exibindo à luz o resíduo entre nascimento e nação, o refugiado faz surgir por um átimo na cena política aquela vida nua que constitui seu secreto pressuposto. Neste sentido, ele é verdadeiramente, como sugere Hannah Arendt, "o homem dos direitos", a sua primeira e única aparição real fora da máscara do cidadão que constantemente é tão difícil de definir politicamente. (AGAMBEN, 2004, p. 138)

O refugiado é, pois, no entre guerras, no pós-guerra e na atualidade, o sujeito que denuncia a urgência do direito a ter direitos. O "homem dos direitos", portanto, desde os sistemas totalitários às democracias atuais, que transformaram em regra o estado de exceção, não é mais o cidadão, mas é o homem sagrado. Nas palavras de Agamben:

Se o refugiado representa, no ordenamento do Estado-nação, um elemento tão inquietante, é antes de tudo porque, rompendo a identidade entre homem e cidadão, entre natividade e nacionalidade, põe em crise a ficção originária da

\footnotetext{
9 As declarações de direitos humanos têm extensão e efetividade relativas. Sua aplicação resulta sempre da disposição de cada Estado-Nação signatário de tais declarações em realizá-la, o que pode ser constante, inconstante ou, mesmo, pode não ocorrer. Além do mais, nem todos os Estados-Nação se comprometem a exercê-las. As declarações são, portanto, proposições universais dotadas de relativo poder coercitivo (para não dizer que ele é praticamente nulo) A afirmação de Arendt sobre o direito de asilo vem ao encontro do que dissemos. Ela escreve: "Assim, não se encontra esse direito na lei escrita, em nenhuma constituição ou acordo internacional, e o Pacto da Liga das Nações nem ao menos o menciona. A esse respeito, tem o mesmo destino da Declaração dos Direitos do Homem, que também nunca em lugar algum foi transformada em lei, levando uma existência mais ou menos irreal, como recurso em certos casos excepcionais em que as instituições legais normais não eram suficientes.” (ARENDT, 2006, p. 314)
} 
soberania. Exceções particulares a esse princípio, naturalmente, sempre existiram: a novidade do nosso tempo, que ameaça o Estado-nação nos seus próprios fundamentos, é que partes crescentes da humanidade não são mais representáveis no seu interior. Por isso, na medida em que se rompe a velha trindade Estado-nação-território, o refugiado, essa figura aparentemente marginal, merece ser, pelo contrário, considerado como a figura central da nossa história política. É importante não esquecermos que os primeiros campos foram construídos na Europa como espaço de controle para os refugiados, e que a sucessão campos de internamento - campos de concentração - campos de extermínio representa uma filiação perfeitamente real. Uma das poucas regras nas quais os nazistas se apoiaram constantemente ao longo da "solução final" era que, só depois de terem sido completamente desnacionalizados (mesmo daquela cidadania de segunda classe que lhe cabia após as leis de Nuremberg), os judeus e os ciganos podiam ser enviados aos campos de extermínio. Quando seus direitos não são mais direitos do cidadão, então o homem é realmente sagrado, no sentido que esse termo tem no direito romano arcaico: votado à morte. (AGAMBEN, 2015, p. 29, 30).

Nos últimos tempos, os ares da mundialização parecem sentir a pressão de uma atmosfera nacionalista cujo ponto de partida, dessa vez, não é a Alemanha ou a Itália. Paradoxalmente, são justamente os que outrora combateram o fascismo e o nazismo, os mais importantes defensores da democracia mundial que, agora, expõem os seus dentes de sabre, dando provas claras de que a tese de que as democracias contemporâneas não fizeram mais do que, no fundo, naturalizar o estado de exceção é, de fato, plausível. As sucessivas decretações de estado de emergência, ocorridas em 2015 e 2016, pelo parlamento francês, como reação imediata aos ataques terroristas; a recente escolha dos ingleses por se apartarem do mercado comum europeu, com lastro na rejeição aos não ingleses; a eleição, pelos norte-americanos, de um representante do nacionalismo radical, que personifica a ideologia da exclusão, de carregada matiz xenofóbica, dão cabal testemunho de que o ethos cosmopolita definitivamente cede espaço para a barbárie. A cosmópole cede espaço para o campo e, com isso, a efetiva cidadania caminha a passos largos para a periferia de parte importante das nações mais poderosas do século XXI fixando-se, em seu lugar, o homo sacer. Ante a perversão da proteção da liberdade, a suspensão da lei e o predomínio da emergência, depara-se com a realidade vivida no território do campo, por ser o espaço que se abre quando o estado de exceção começa a tornar-se regra na hodiernidade.

No mundo secularizado, o poder soberano se ergue sobre a necessária exclusão de seres humanos - "que nas línguas européias modernas, indica os pobres, os deserdados, os excluídos. Denominando também o sujeito político constitutivo quanto a classe que, de fato, se não de direito, é excluída da 
política” (AGAMBEN, 2002, p. 183) - na qual o biopoder instaura uma zona indeterminada, para onde são lançados os excluídos desse sistema.

\section{CONSIDERAÇÕES FINAIS}

O fenômeno basal do poder soberano é a produção da vida nua como elemento político original e como limiar de articulação entre natureza e cultura, zoé e bíos. Logo, a política ocidental é, desde o início, uma biopolítica e, deste modo, torna-se vã toda tentativa de fundamentar nos direitos do cidadão as liberdades políticas. Esse espaço sagrado incongruente criado pela política gera o ofuscamento nas atitudes de discernir as realidades existenciais, através da subsunção do sagrado pela política hodierna secularizada.

Nesta perspectiva, o modelo de secularização atual coopera para justificar as gestões políticas dos pequenos grupos características dos regimes totalitários, possibilitando sua aceitação social, tornando rotineira a inacessibilidade dos sujeitos aos mecanismos institucionais que, por princípio, deveriam estar à disposição de todos. Esta experiência desencadeia uma "síndrome" denominada como "normose", em que as pessoas movimentam-se através da lei da inércia, em uma postura descompromissada e acrítica.

Tal "normose" é responsável pela geração do homo sacer, a mais paradoxal de todas as figuras contemporâneas. A condição de vida nua invoca a reflexão sobre o ser humano a partir de sua condição carnal, tendo como premissa o sentido de carne $(\operatorname{sar} x)^{10}$ apresentado por Paulo de Tarso. Desprovido de enfoque propriamente espiritual, o termo indica a fraqueza de uma humanidade constituída como carne e sempre vulnerável à manipulação dos seus desejos e necessidades carnais, vinculada a certa identidade social. Infere-se, daí, que a humanidade como sarx é frágil a interesses ilícitos de demagogias nacionalistas de toda espécie. Na concepção paulina, a pessoa é ser que atua dentro de várias dimensões, como seres corporificados, sociais, definidos em parte pela necessidade e capacidade de entrar em relação mútua, como uma dimensão inerente à existência humana. A carnalidade atesta a debilidade e a potência dos seres humanos: a fragilidade daqueles que não podem evitar a morte - a finitude - e que são vulneráveis e dependentes da satisfação dos apetites e dos

\footnotetext{
${ }^{10}$ Em uma perspectiva teológica, o que mais caracteriza o Deus de Jesus é sua humanidade, ou seja, o Deus que se revelou em Jesus, pode ser encontrado antes de tudo no humano, mais que no sagrado, no religioso ou no espiritual, como algo contraposto ao que é pura e simplesmente humano. Consequente, o Deus de Jesus se encontra, antes de tudo no laical - no cotidiano da vida -, não no sagrado, no religioso ou no espiritual. Com isso, o sagrado, o religioso e o espiritual são autênticos, aceitáveis e instrumentos para encontrar a Deus quando humanizam e tornam o indivíduo mais humano. (CASTILLO, 2015).
} 
desejos; a racionalidade, que capacita o homem para o pensamento reflexivo; e a afetividade, na medida em que são dotados de sentimentos, aptos a experienciar profundas emoções. As pessoas também são animadas pelo mistério da vida, que se manifesta como um dom, e há uma dimensão do ser tocada pela realidade mais profunda dentro e além do universo (DUNN, 2003). A concepção e a consciência de ser humano apresentam, pois, elementos que ressoam na intimidade inerente entre a fragilidade e a potencialidade do indivíduo, a partir de sua carnalidade, alteridade e liberdade. Animados pela inquietude e criatividade, os seres humanos experienciam a humanidade e podem gerar uma sociedade humanizadora e, por conseguinte, humanizada. Destituído da possibilidade de se relacionar socialmente, o homo sacer, todavia, não perde as características fundamentais do sarx, a saber, a fraqueza, de um lado, e a potencialidade, de outro. Se a vida nua corresponde - nas esferas social, política e econômica - ao fantasma vivo, ela não deixa de ser vida de ser humano. O homo sacer é aquele que está no limiar entre o biós e a zoé, mas nem por isso perde a sua condição de carnalidade, a potencialidade de sentir e de refletir, de um lado, e a impotência diante da morte, de outro. A sua condição extrema revela algo verdadeiramente excepcional: se não encontra mais forças para refletir ou mesmo sentir - embora ainda possua a potência para fazê-lo na sua absoluta debilidade evidencia a sua maior força, ou seja, a sua sobrevivência. O homo sacer situa-se no limite entre o material e o transcendente, na medida em que, abandonado, também abandona parte de sua própria condição humana - a disposição para refletir, a vontade de sentir e até mesmo a necessidade de satisfazer os apetites e os desejos próprios da carne. $\mathrm{E}$ justamente por ser profundamente sarx é, também, a sua negação, suspendendo o temor à morte, desafiando-a a cada milésimo de segundo. $\mathrm{O}$ homo sacer revela a mais profunda humanidade do ser humano ao mesmo tempo em que inspira ações e sentimentos humanitários. Ele é a fragilidade da carne que depõe o cinismo do outro (o homem pleno, o biós), invocando, com isso, certo tipo de alteridade que encontra meios de se realizar pelos direitos humanos. É livre de todas as leis - porque está muito longe de acessá-las - mas, ao mesmo tempo, é refém da força do poder soberano que o esmaga no exílio em que é lançado e, por isso mesmo, dialeticamente, alcançado pela própria lei da qual está privado. Não pode testemunhar, porque não é ouvido, porque sua voz não tem qualquer importância. Todavia, seu corpo fala por si mesmo: é o testemunho da exclusão inclusiva, a pérola do mundo ressentido que marca a memória mais recente da humanidade. 
Por ironia, o esquecido é justamente aquele que está aí para que não se esqueça, o sujeito que não pode testemunhar e que, apesar de banido, subsiste. É urgente que a humanidade se poste defronte ao espelho, enxergando à sua frente o que teima em desaperceber: o ressentimento. Já passa do tempo em que se deve superar a sacralização do profano, motivo do comportamento obtuso das massas, promovendo-se o seu contrário, a profanação do sagrado, ao torna-se de uso comum todas as coisas que foram, um dia, retiradas do acesso dos homens.

\section{REFERÊNCIAS}

AGAMBEN, Giorgio. Homo Sacer: o poder soberano e a vida nua. v. I. Belo Horizonte: Editora UFMG, 2002.

O Reino e a Glória: uma genealogia teológica da economia e do governo. São Paulo: Boitempo, 2012.

Estado de Exceção. São Paulo: Boitempo, 2005.

2008.

O que resta de Auschwitz: o arquivo e a testemunha. São Paulo: Boitempo,

Ideia da prosa. Belo Horizonte: Autêntica Editora, 2013.

Profanações. São Paulo: Boitempo, 2007.

Une biopolitique mineure: entretien avec Giorgio Agamben. Disponível em: <http://www.vacarme.org/article255.html>. Acesso em: 04 jun. 2016.

AGUILERA, Julio Fausto. A batalha do verso. Disponível em: <http://poeticas.es/?p= 2710>. Acesso em: 06 jun. 2016.

ARENDT, Hannah. Origens do Totalitarismo: anti-semitismo, imperialismo, totalitarismo. 6a. reimpressão. São Paulo: Cia das Letras, 2006.

BENJAMIN, Walter. Crítica da violência - Crítica do poder. In: BENJAMIN, Walter. Documentos de cultura, documentos de barbárie: escritos escolhidos. São Paulo: Edusp; Cultrix, 1986.

CASTILLO, José Maria. Jesus: a humanização de Deus - ensaio de cristologia. Petrópolis: Vozes, 2015.

DUNN, James D. G. A teologia do apóstolo Paulo. São Paulo: Paulus, 2003.

FOUCAULT, Michel. Microfísica do poder. Rio de Janeiro: Graal, 1979.

Em defesa da sociedade. São Paulo: Martins Fontes, 2005.

GIACOIA JUNIOR, Oswaldo. Messianismo e Política em Giorgio Agamben.

Revista Reflexão, Campinas, v. 40, n. 1, p. 7-20, jan./jun., 2015. 
Nietzsche. São Paulo: Publifolha, 2000.

. Nietzsche - A morte de Deus. Disponível em: < https://www.youtube.com /watch?v=2igSooIHj9Y>. Acesso em: o8 jan. 2017.

NIETZSCHE, Friedrich. A Genealogia da Moral. 4. ed. Lisboa: Guimarães \& C. ${ }^{\text {, }}$ 1983. Vozes, 2014.

Além do bem e do mal: prelúdio de uma filosofia do futuro. Petrópolis:

A Gaia Ciência. 2. ed. São Paulo: Companhia das letras, 2001.

OLIVEIRA, Salete. Notas para a abolição dos campos de concentração e de extermínio. Verve, 7: 43-56, 2005. Disponível em: <http://revistas.pucsp.br /index.php/ verve/article/view/ 5019>. Acesso em: o4 nov. 2016.

PEREIRA, José Carlos. Resiliência: para lidar com pressões e situações adversas. São Paulo: Ideias \& Letras, 2015.

VEDOVATO, Luís Renato. O direito de ingresso do estrangeiro: a circulação das pessoas pelo mundo no cenário globalizado. São Paulo: Atlas, 2013. Disponível em: <http: //www.academia.edu/9866054/O_Direito_de_Ingresso_do_Estrangeiro >. Acesso em: 09 fev. 2017.

VIDAL, Marciano. O Evangelho da vida: para uma leitura da Evangelium vitae. São Paulo: Paulinas, 1997.

WILLIAMS, Philip F. and WO, Yenna. The great wall of confinement: the chinese prison camp through contemporary fiction and reportage. Berkley and Los Angeles, California: University of California Press; London, England: University of California Press Ltda, 2004. Disponível em: <https://books.google.com .br/books?hl=ptBR\&lr=\&id=HyLRqvyz2DUC\&oi=fnd\&pg=PP1\&dq=related:HCRcAsT pEGoJ:scholar.google.com/\&ots=znv7lUVY6h\&sig=nDHU39sI5v_7bi_xA-cV-6oVt $\mathrm{bI} \# \mathrm{v}=$ onepage\&q\&f=false $>$. Acesso em: 05 nov. 2016. 